\title{
Why Have Multiple Plastic Responses? Interactions between Color Change and Heat Avoidance Behavior in Battus philenor Larvae
}

\author{
Matthew E. Nielsen ${ }^{\star}$ and Daniel R. Papaj \\ Department of Ecology and Evolutionary Biology, University of Arizona, Tucson, Arizona \\ Submitted August 9, 2016; Accepted January 6, 2017; Electronically published March 28, 2017 \\ Online enhancements: appendix. Dryad data: http://dx.doi.org/10.5061/dryad.ph826.
}

\begin{abstract}
Having multiple plastic responses to a change in the environment, such as increased temperature, can be adaptive for two major reasons: synergy (the plastic responses perform better when expressed simultaneously) or complementarity (each plastic response provides a greater net benefit in a different environmental context). We investigated these hypotheses for two forms of temperature-induced plasticity of Battus philenor caterpillars in southern Arizona populations: color change (from black to red at high temperatures) and heat avoidance behavior (movement from host to elevated refuges at high host temperatures). Field assays using aluminum models showed that the cooling effect of the red color is greatly reduced in a refuge position relative to that on a host. Field assays with live caterpillars demonstrated that refuge seeking is much more important for survival under hot conditions than coloration; however, in those assays, red coloration reduced the need to seek refuges. Our results support the complementarity hypothesis: refuge seeking facilitates survival during daily temperature peaks, while color change reduces the need to leave the host over longer warm periods. We propose that combinations of rapid but costly short-term behavioral responses and slow but efficient long-term morphological responses may be common when coping with temperature change.
\end{abstract}

Keywords: phenotypic plasticity, temperature, color, behavior, functional integration, Battus philenor.

\section{Introduction}

Phenotypic plasticity is the capacity of organisms to produce different phenotypes in response to different environments. Such plasticity is considered to be adaptive if it enables plastic genotypes to maintain higher fitness across multiple environments than less plastic genotypes (Ghalambor et al. 2007). Although phenotypic plasticity is typically studied with reference to a single trait, organisms can often respond to a given environmental change with adaptive plastic responses in mul-

\footnotetext{
* Corresponding author; e-mail: maerniel@live.unc.edu.
} ORCIDs: Nielsen, http://orcid.org/0000-0002-0388-1187.

Am. Nat. 2017. Vol. 189, pp. 657-666. (C) 2017 by The University of Chicago. 0003-0147/2017/18906-57159\$15.00. All rights reserved. DOI: $10.1086 / 691536$ tiple distinct traits, ranging from morphology to physiology to behavior (Schlichting 1989; Boersma et al. 1998; Relyea 2004; Foster et al. 2015). These plastic responses often include behavior itself as an immediate response to environmental changes (activational plasticity, sensu Snell-Rood 2013) as well as longer-term developmental changes. For example, tadpoles of Hyla chrysocelis (gray treefrog) and many other amphibian larvae respond to the presence of predators immediately by reducing activity level and more slowly by changing tail shape (McCollum and Van Buskirk 1996; Van Buskirk and McCollum 2000; Kishida et al. 2010). Nevertheless, each form of plasticity potentially incurs its own costs (DeWitt et al. 1998; Auld et al. 2010). Why, then, would an organism have plasticity in multiple, independent traits, all of which serve the same general function? This question has, to our knowledge, never been directly addressed, and answering it requires an understanding of the different ways plastic responses could affect each other.

In this study, we propose and evaluate two general hypotheses to explain why organisms might have multiple plastic traits addressing a particular function: synergy and complementarity. The synergy hypothesis states that the different plastic responses perform their shared function better when expressed simultaneously. Synergy can occur if the traits in question are functionally integrated. Functional integration occurs when the performance of a function depends on the interaction of multiple traits and is maximized by a particular combination of the traits' phenotypes (Cheverud 1996). If plastic traits are functionally integrated, then changing both simultaneously in response to an environmental change will yield a greater improvement in performance than the sum of changing each trait alone. Synergy can also occur if there are limits on the ability to change a single trait and thus on its performance (DeWitt et al. 1998), in which case additional change in a second trait can allow a greater overall functional response and improved performance even if the traits function independently. 
In contrast to the synergy hypothesis, the complementarity hypothesis states that each plastic response provides a greater benefit under different environmental conditions. Even if plasticity in one trait performs better unconditionally, a less effective but less costly trait change might be more appropriate in some circumstances. Plastic traits also vary in how quickly the trait value can change (Piersma and Drent 2003). Whereas theory predicts that a faster change will be better if the environment changes frequently (Padilla and Adolph 1996), a slower change may be more suitable for long-term environmental changes if it is more effective or less costly.

While multiple plastic changes can occur in response to any aspect of the environment, how organisms respond to temperature change provides an ideal context for evaluating these two hypotheses. Temperature constitutes a critical aspect of any organism's environment, affecting processes ranging from biochemistry to life history, yet it varies on many different temporal and spatial scales, from across years to within days and from across continents to within centimeters (Kingsolver 2009). This variability favors plasticity in responses to temperature, and in fact, plasticity can occur in many different thermoregulatory traits, from morphology to physiology to behavior (Stevenson 1985; Kingsolver and Huey 1998). Despite the large number of potentially plastic traits involved in thermoregulation, interactions among them have received little empirical investigation (Gvozdik 2012). A number of studies, however, have looked at how thermoregulatory behavior interacts with nonplastic color variation and its consequences for temperature in a variety of insects (Kingsolver 1985, 1987; Forsman 2000; Forsman et al. 2002; Ahnesjö and Forsman 2006; Lindstedt et al. 2009). Nevertheless, of these studies, only Kingsolver $(1985,1987)$ characterized the functional interactions between these traits, and, pertinent to our work, even that study did not address how distinct forms of plasticity interact in thermoregulation.

Caterpillars of the pipevine swallowtail Battus philenor are particularly well suited for investigating how multiple plastic responses to temperature might interact, because they possess two distinct plastic responses to high temperatures. First, these caterpillars can reversibly change color each time they molt, developing red body coloration when raised above $36^{\circ} \mathrm{C}$ and black coloration at or below $30^{\circ} \mathrm{C}$ (fig. A1A, A $1 B$; figs. A1-A3 available online; Nice and Fordyce 2006). Because red caterpillars reflect more solar radiation than black ones, red caterpillars warm more slowly and reach lower asymptotic body temperatures (Nice and Fordyce 2006). Second, caterpillars avoid high temperatures behaviorally, seeking refuges. In southern Arizona, where our study is based, caterpillars leave their ground-hugging host plants and climb to a higher, cooler location in nonhost vegetation, where body temperature can be reduced by as much as $10^{\circ} \mathrm{C}$ (Nice and Fordyce 2006; Nielsen and Papaj 2015). This behavior ultimately makes caterpillar temperature less variable than the temperature of their host (Nielsen and Papaj 2015).

Either synergy or complementarity could account for B. philenor having both color change and refuge-seeking behavior. In the southwestern United States, daily temperature highs can be extreme, potentially higher than either trait alone could compensate for. Synergy between the responses might enable caterpillars to better survive these extreme temperatures. Alternatively, color change and refuge seeking might be complementary ways of responding to high temperatures, with each trait being better suited to responding to temperature variation at different timescales. Larvae can change color only when they molt, which occurs at most once per day under ideal laboratory conditions and typically over multiple days in nature (M. E. Nielsen, personal observation). Hence, color change occurs too slowly to respond to daily temperature fluctuations. On the other hand, refuge-seeking behavior can respond quickly, on the order of minutes, but exacts a potentially heavy cost in requiring caterpillars to leave their host plants. Not only must caterpillars stop eating while on a thermal refuge, but they incur a substantial risk of not locating a host after they leave one (Rausher 1979).

In this study, we tested the synergy and complementarity hypotheses in $B$. philenor, using two experiments. First, we used painted aluminum caterpillar models to experimentally simulate the effects of both color and position in the vegetation on body temperature and test for any functional interaction between these plastic traits. Then, using live caterpillars in field enclosures, we tested whether and how body coloration and refuge availability interact to affect survival and also whether body coloration influences the expression of refuge-seeking behavior. The two tests together permitted us to evaluate which of these hypotheses, or whether both, accounted for the occurrence of these two plastic responses to high temperatures in the butterfly's larval stage or whether both contributed.

\section{Methods \\ Study Organism and Field Site}

Battus philenor L. larvae undergo five instars during development, ranging in mass from $\sim 2 \mathrm{mg}$ (first instar) to greater than 2,000 mg (late fifth instar). These caterpillars feed only on plants in the genus Aristolochia, from which they sequester aristolochic acids that defend them from vertebrate and invertebrate predators (Sime et al. 2000). Both color forms of the caterpillar are conspicuous and thought to function as warning colors. In southern Arizona, Aristolochia watsonii Wooton \& Standl. (Watson's pipevine) is the lone wild representative of its genus and thus the caterpillars' only wild host. Aristolochia watsonii is a small perennial with procumbent, fully deciduous vines. It grows from low to middle elevations, often in washes and nearby areas. In south- 
ern Arizona, B. philenor has four broadly overlapping broods from March to September before overwintering as pupae; however, the timing and discreteness of broods varies substantially from year to year and site to site, and adults are occasionally observed even in midwinter. This phenology exposes all life stages to a wide range of temperatures across generations.

All of our field experiments were conducted on a 25-ha site in Pasture 1 at the University of Arizona Santa Rita Experimental Range in Pima County, Arizona $\left(31^{\circ} 47.049 \mathrm{~N}, 110^{\circ}\right.$ 49.524W). The site consists of mesquite grassland with an introduced grass, Eragrostis lehmanniana (Lehmann's lovegrass) as the dominant species. Aristolochia watsonii is locally abundant, although often obscured by the overlaying vegetation. Wild caterpillars of both color forms can be observed at this site, with relative abundance heavily depending on time of year. Refuge-seeking behavior also occurs frequently, with the dominant grasses providing the usual refuge.

\section{Physical-Model Experiment}

To test the interaction between the effects of color and position on caterpillar temperature, we used red- and blackpainted aluminum as operative-temperature models of the caterpillars (fig. A1C; Nielsen and Papaj 2015). Operative temperature summarizes the different ways the environment can affect temperature (e.g., thermal radiation, air temperature, wind speed) but also depends on particular physical properties of the object itself: specifically, its size, shape, and color, but, importantly, not its composition (Bakken et al. 1985; Bakken 1992). In the absence of substantial metabolic heat or evaporation, reasonable assumptions for a caterpillar, operative temperature will equal an organism's body temperature at equilibrium (Bakken et al. 1985; Bakken 1992). For our study, the operative-temperature models were solid aluminum cylinders $48 \mathrm{~mm}$ long and $7.9 \mathrm{~mm}$ in diameter, corresponding to the size of a late-fifth-instar caterpillar. The black color was produced with black acrylic paint (Bone Black, Golden Acrylics), while the red color was produced with a 3:1 mixture of red (Red Oxide, Golden Acrylics) and black acrylic paint. We selected both colors to resemble the spectra of red and black caterpillars as closely as possible (fig. A2). We also specifically selected high-emissivity paints; in infrared images, the temperatures measured for both colors of paints were indistinguishable from that of masking tape (with known emissivity of 0.95 ) placed on the same model, and so we set $\varepsilon=0.95$ for all analyses. Compared under full sun, models were $0.5^{\circ} \mathrm{C}$ warmer than live caterpillars, and this difference was independent of color (see "Verification of Aluminum Models of Caterpillars" in the appendix, available online, for more details). This calibration also confirmed that live black caterpillars were warmer than red ones at equilibrium. We attached pairs of same-colored models to 3.2-mm-diameter wooden dowels, using minimal quantities of hot glue, one model in a position corresponding to a caterpillar on a host plant (horizontal, $10 \mathrm{~mm}$ above the ground) and the other in a position corresponding to a caterpillar on a thermal refuge (vertical, $248 \mathrm{~mm}$ above the ground, the median height of refuge-seeking caterpillars observed previously; Nielsen and Papaj 2015).

On June 8 and July 5 and 6,2016, we placed sets of models at eight locations in our field site near known $A$. watsonii plants, with at least $0.5 \mathrm{~m}$ between locations. Each set of models consisted of a pair of black models and a pair of red models, with the two pairs of models placed $\sim 10 \mathrm{~cm}$ apart (fig. A1C). We determined which colored pair was placed at a specific point randomly. Each day we reassigned each pair of models to a new spot within its location. Each model's length faced south, minimizing shade from the dowel, and we specifically chose positions that avoided extensive shading by the surrounding grass. Models had at least $30 \mathrm{~min}$ to equilibrate, which preliminary trials indicated was sufficient for models to reach equilibrium (see "Verification of Aluminum Models of Caterpillars" in the appendix). Measurements were made every half-hour on each model between 09:00 and 12:00. For each measurement, we recorded an infrared image with a thermal imaging camera (T-300, FLIR) at a distance of approximately $12 \mathrm{~cm}$ and noted the time. We also recorded infrared images of two pairs of unpainted aluminum models, which we used to estimate the effect of reflected infrared radiation from the environment on our readings (see below). The weather was sunny for all measurements (i.e., clouds never obscured the sun), except for 11:0012:00 on July 6, which was excluded from analysis. Models occasionally fell off the dowels; we excluded all further measurements of these models from analysis, excluding a total of 17 black measurements and 24 red and giving us a final total of 447 measurements made on 28-32 models on each of 3 days.

To assess model temperature, we used FLIR Quick Report (ver. 1.2) to set each image's emissivity to 0.95 and its reflected temperature to the temperature of the nearest aluminum model in the same position during the same round of measurements. Next, we estimated mean model surface temperature as precisely as possible by freehand selection of all but the edges of the model in ImageJ (ver. 1.45s). The effects of model color, model position, time of day, and their interactions on model temperature were analyzed with a generalized mixed-effects model. The three-way interaction among these factors was nonsignificant $(P=.67)$, while the interaction between color and time of day was only nearly significant $(P=.08)$ and small $\left(0.28^{\circ} \mathrm{C} / \mathrm{h}\right)$; thus, both interactions were excluded from the final analysis. As random effects we used individual model, nested within set of models, nested within day, and we also allowed variance itself to depend on model position. All statistical analyses were con- 
ducted in R (ver. 3.1.2), and the "lme" procedure in the nlme package was used for this generalized mixed-effects analysis.

\section{Live-Caterpillar Experiment}

To test the effect of color on refuge-seeking behavior as well as the joint effect of color and behavior on caterpillar survival, we conducted a field experiment with lab-reared caterpillars. Eggs were obtained from butterflies caught directly at the field site, from their descendants, or from butterflies collected as caterpillars on the University of Arizona campus. Eggs were initially kept at $30^{\circ} \mathrm{C}$. Hatchlings were raised at either $30^{\circ} \mathrm{C}$ (a black-producing temperature) or $38^{\circ} \mathrm{C}$ (a red-producing temperature). Caterpillars in both temperature regimes were kept in plastic boxes in stand-alone growth chambers with a 12L:12D light-dark cycle. They were fed freshly collected leaves of Aristolochia fimbriata ad lib. and, upon reaching the fourth instar, were haphazardly selected for use in the field experiment.

For the field experiment, we located 40 wild A. watsonii hosts at our field site and placed an open-top enclosure, $50 \mathrm{~cm} \times 50 \mathrm{~cm} \times 15 \mathrm{~cm}$ tall and made of $1.6-\mathrm{mm}$-thick clear acrylic sheet, around each of the plants (fig. A3). These dimensions were large enough that the $A$. watsonii rarely touched the edge of the enclosure. The walls were thinly coated with petroleum jelly $\sim 3 \mathrm{~cm}$ above the ground to inhibit the caterpillars from climbing them. In all enclosures, we clipped all nonhost vegetation to ground level so it could not be used as a thermal refuge; in half of them (chosen randomly), we placed four $50-\mathrm{cm}$-tall wooden dowels to serve as artificial thermal refuges, two adjacent to the plant and two at opposite corners of the enclosure $\sim 2 \mathrm{~cm}$ from the edge. This generated refuge-available and refuge-unavailable treatments.

At the start of the experiment, caterpillars were weighed and then placed on the host plant inside an enclosure either between 17:00 and 18:00 the evening before or between 07:00 and 8:00 the morning of the main experiment (depending on when exactly the caterpillars reached the fourth instar). Half of the enclosures in each refuge availability treatment (chosen randomly) received a red caterpillar and half a black one, resulting in a $2 \times 2$ factorial design with 10 individuals in each of the four treatment combinations. Starting at 08:00 and given at least $30 \mathrm{~min}$ to acclimate, we walked a fixed circuit of the enclosures every hour, until 18:00. During each circuit, we recorded the position and activity of each caterpillar, took thermal images of the ground, and measured ambient temperature with a shaded thermocouple (Omega, HH502, Type-K bead wire). Any caterpillars that had begun climbing the enclosure (despite the petroleum jelly) were returned to the host. Enclosures whose residents had died or escaped were skipped in future circuits. Twenty-four hours after we originally placed the caterpillars in the enclosures, we noted whether they had died of overheating during that time or sur- vived, excluding from analysis for survival the 8 caterpillars that went missing, 12 that died of other causes, and 2 disrupted by external factors (e.g., cows). We presumed that death was due to overheating if we found a desiccated corpse; in some cases, we observed behavioral signs of thermal stress (rapid movement, leaving the host, uncontrolled spasms) before death. This experiment was repeated fully on 8 days (September 2, 16, and 30, 2013; July 13, 2014; and May 22 and June 12, 15, and 18,2015), with an additional 3 days (July 27 and August 5 and 8,2015) considered only for survival to better sample the full range of peak daily temperatures. Host plants were reused across days within a year so long as they had at least two growing stems, in which case repetition of treatment combinations for each plant was minimized, but otherwise they were assigned a new treatment randomly.

In order to assess ground temperature from the thermal images, we averaged the temperatures of the vertices and midpoints of a rectangle superimposed on the ground, surrounding the host in ImageJ (ver. 1.45s). We used generalized mixed models with a binomial distribution to test effects on both refuge use and survival, calculated with the "glmer" procedure in the lme4 package. To test effects on refuge use, we considered only caterpillars with access to refuges and considered them to be using a refuge if they were above $10-\mathrm{cm}$ height on it. For this analysis, we used color, ground temperature, their interaction, and plant height as fixed effects. Caterpillar nested within date was a random effect. Color's interaction with plant height was nonsignificant $(P=.90)$ and excluded from the final model. To test effects on survival, we used color, refuge availability, and their interaction as fixed effects, in addition to plant height and daily high temperature as assessed by a weather station within $0.5 \mathrm{~km}$ of our field site (detailed in Scott et al. 2009); date and enclosure were used as crossed random effects. The $P$ values for fixed parameters were calculated with likelihood ratio tests and a procedure analogous to Type II sums of squares and were not calculated for individual effects in cases of significant interaction. All interactions with daily high temperature for the survival model and all interactions with plant height in both models were either nonsignificant $(P>.40)$ or could not be estimated and were not the focus of our study, so they were excluded from the final models.

\section{Results \\ Physical Models}

Across three days, we recorded 447 temperature measurements from 92 models. Model position, color, and time of day all affected model temperature (fig. 1), with significant interactions between position and color and between position and time. More specifically, the cooling effects of being on a refuge and being red were reduced significantly in com- 


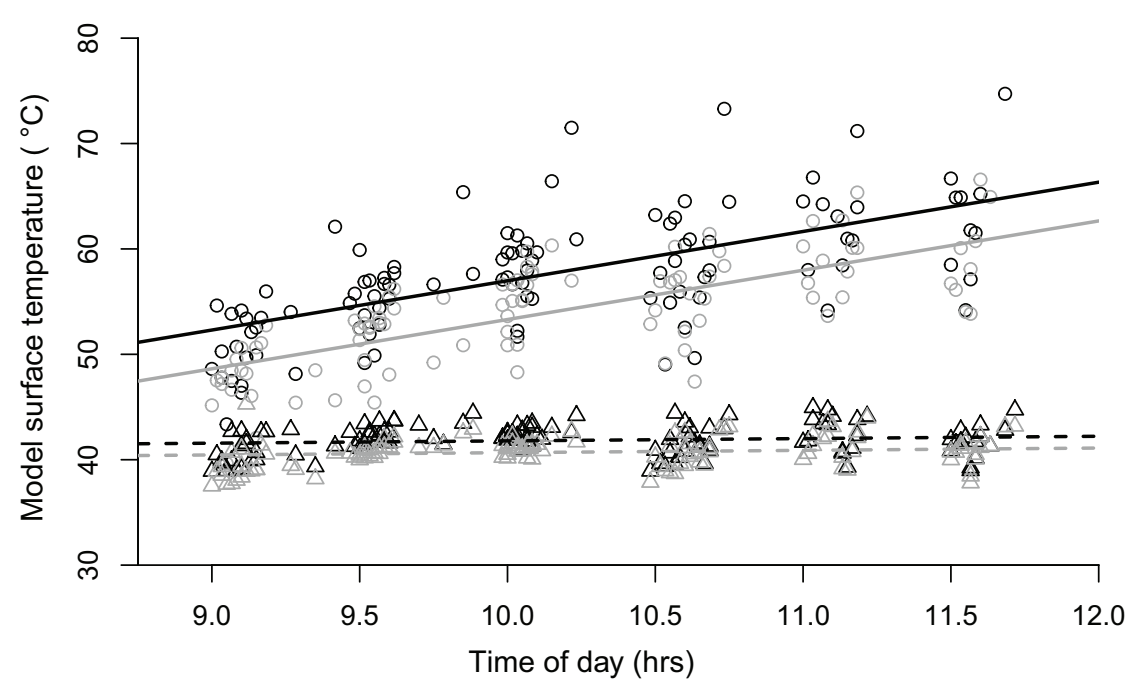

Figure 1: Effects of color, position, and time of day on the mean surface temperature of aluminum caterpillar models. Gray lines and points represent red models; black ones represent black models. Circles and solid lines represent models in a position similar to being on a host; triangles and dashed lines represent models in a typical refuge-seeking position. Points represent individual measurements, while lines represent predicted temperatures. From a total of $n=447$ observations of 32 models in 92 different specific locations across 3 days.

bination, such that red models were $3.7^{\circ} \mathrm{C}$ cooler than black ones in a host position but only $1.1^{\circ} \mathrm{C}$ cooler in a refuge position (fig. 1 ; color $\times$ position: $F_{1,63}=8.57, P=.0047$ ). The cooling benefit of refuge seeking increased significantly as the day grew hotter (position $\times$ time of day: $F_{1,356}=$ $272.5, P<.0001$ ); red models were $8.2^{\circ} \mathrm{C}$ cooler on a refuge than on a host at $09: 00$ versus $20.4^{\circ} \mathrm{C}$ cooler at $11: 45$, with both differences $2.6^{\circ} \mathrm{C}$ greater for black models. This result meant that "body" temperatures remained nearly constant on refuges; red models ranged from a mean temperature of $39.5^{\circ} \mathrm{C}$ during the first round of measurements (09:00$09: 30)$ to $40.9^{\circ} \mathrm{C}$ during the last round (11:30-12:00), while mean temperatures for black models ranged from $40.8^{\circ} \mathrm{C}$ to $42.0^{\circ} \mathrm{C}$ over the same time frame. Overall, color had a much smaller effect on temperature than refuge seeking; even the smallest effect of refuge seeking on model temperature $\left(8.2^{\circ} \mathrm{C}\right.$ for red models at 09:00) was more than double the greatest effect color change could produce $\left(3.7^{\circ} \mathrm{C}\right.$ on the host plant, regardless of time).

\section{Live Caterpillars}

Overall, we tested 400 caterpillars in our field experiments. We observed the behavior of 148 of these caterpillars that had access to thermal refuges, for a total of 1,281 observations. Overall, black caterpillars were found on refuges in $46.4 \%$ of observations, versus only $34.1 \%$ of observations for red caterpillars. Caterpillars of both colors used refuges much more often with increasing ground temperature; however, there was a significant interaction between color and temperature, in which black caterpillars were found more often on refuges than red caterpillars as temperatures increased (fig. 2; table 1). This decreased refuge seeking by red caterpillars corresponded to these caterpillars spending, on average, $5.15 \mathrm{~h}$ on their hosts during the observed time period of $8 \mathrm{~h}, 1.32$ more hours than the $3.83 \mathrm{~h}$ black caterpillars spent on their hosts. Finally, caterpillars were observed less frequently on a refuge when their host plants were taller, a strongly significant pattern (table 1).

Caterpillar survival depended significantly on the high temperature of the test day, caterpillar color, and refuge availability (fig. 3; table 2). Both caterpillar color and refuge availability were associated with higher caterpillar survival, but refuge availability had a 2.65 times larger effect size (table 2). There was no significant interaction between caterpillar color and refuge availability (table 2), probably because death from overheating was rare when refuges were available (7 out of 202 individuals, 3.5\%), and in four of these cases the doomed caterpillar was on the ground the last time it was observed alive, suggesting that it died unable to find a refuge rather than while on one. Finally, caterpillars with taller host plants also survived more frequently (table 2). All data from all parts of this study are available from the Dryad Digital Repository: http://dx.doi.org/10.5061/dryad.ph826 (Nielsen and Papaj 2017).

\section{Discussion}

Although color change and refuge-seeking behavior each helped Battus philenor caterpillars avoid overheating in our 


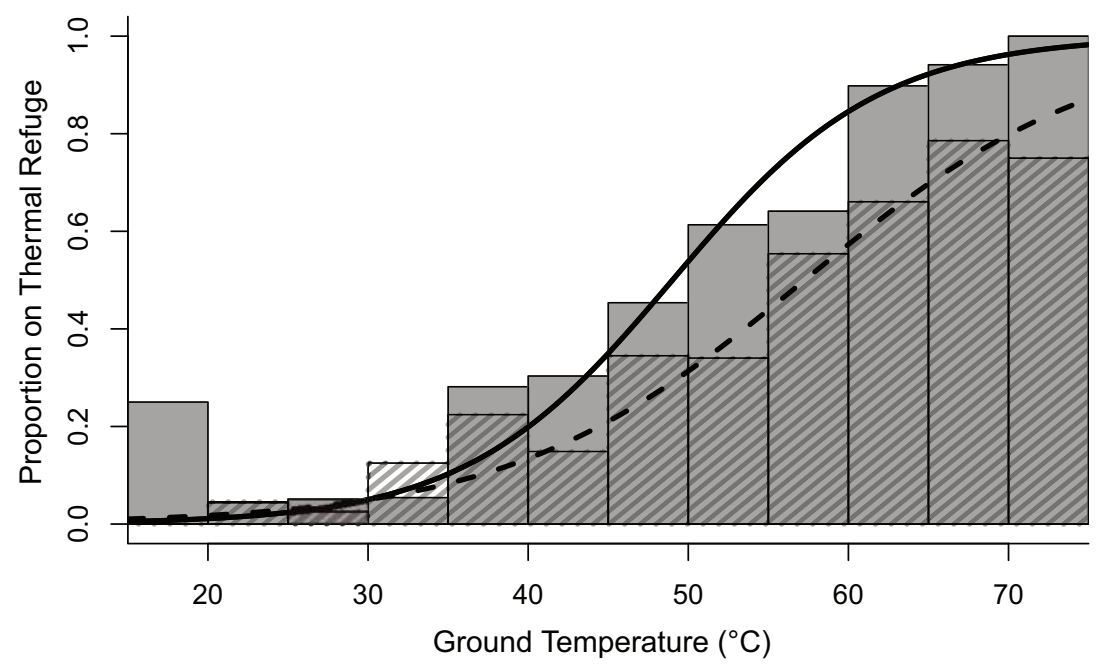

Figure 2: Effects of color and ground temperature on thermal-refuge seeking by Battus philenor caterpillars. The dashed line and striped bars represent red caterpillars; the solid line and shaded bars represent black caterpillars. Bars represent the proportion of caterpillars observed on refuges at a particular ground temperature; lines represent predicted probabilities of being on a refuge. $N=1,282$ observations of 148 caterpillars.

study, we can reject the synergy hypothesis because the effect of color change on body temperature was largely redundant with the much larger effect of thermal refuge-seeking behavior on both temperature and survival in our experiments. The joint effect of changing color and position was less than the sum of their separate effects, with red color cooling models less when in a refuge-seeking position than when in a host position. Hence, not only is color change not beneficially functionally integrated with thermal refuge seeking, but color change also can do little to overcome any limitations on the ability to reduce temperature behaviorally. This inference is reinforced by the fact that having access to refuges resulted in nearly complete survival, even at the hottest times of year. Further, red color reduced rather than increased refuge-seeking behavior. If the two changes were synergistic, we would have expected positively correlated expression.

Instead, our data support the complementarity hypothesis; color change and refuge seeking each provide more effective responses to different patterns of environmental change, specifically different timescales and magnitudes of temperature change. In our study, red caterpillars sought thermal refuges at higher temperatures than did black ones, resulting in less time overall on thermal refuges and more time on the host. This negative effect of color on expression of refuge seeking would be expected if the two responses perform best under different conditions (rather than when combined).

Because we produced the different colors by raising the caterpillars at different temperatures, the change in behavior between treatments could have been caused by other plastic physiological responses to these treatments (e.g., acclimation of preferred temperature). Additional work, however, shows that the different colors themselves cause the change in behavior solely through their effect on the caterpillars' body temperature and that developmental temperature has no other discernible effect on the caterpillars' behavioral response to temperature (Nielsen 2016). Specifically, caterpillars raised under the same conditions as in this study seek thermal refuges at the same body temperature regardless of the temperature they were raised at (and thus their color), and developmental temperature influences only the duration of heating required for caterpillars to start refuge-seeking behavior under conditions in which color can affect that heating (i.e., heating with light as opposed to conduction; Nielsen 2016).

The advantages of thermal refuge-seeking behavior are clear. We found that refuge-seeking behavior has the ability to create a much greater body temperature change than does color change and is also the faster response, occurring over minutes rather than the day or more required for color change. These facts suggest that thermal refuge-seeking behavior is

Table 1: Effects of caterpillar color, ground temperature, and plant height on likelihood of a caterpillar being observed on a thermal refuge

\begin{tabular}{|c|c|c|c|c|}
\hline & Coefficient & SE & $\chi^{2}$ & $P$ \\
\hline Color $^{\mathrm{a}}$ & 1.400 & .911 & $\ldots$ & \\
\hline Ground temperature $\left({ }^{\circ} \mathrm{C}\right)$ & .155 & .0143 & $\ldots$ & .. \\
\hline Plant height $(\mathrm{cm})$ & -.288 & .0676 & 18.38 & .00002 \\
\hline $\begin{array}{l}\text { Color }{ }^{\mathrm{a}} \times \text { ground } \\
\text { temperature }\left({ }^{\circ} \mathrm{C}\right)\end{array}$ & -.047 & .0181 & 6.75 & .00939 \\
\hline
\end{tabular}

\footnotetext{
${ }^{a}$ Red versus black.
} 

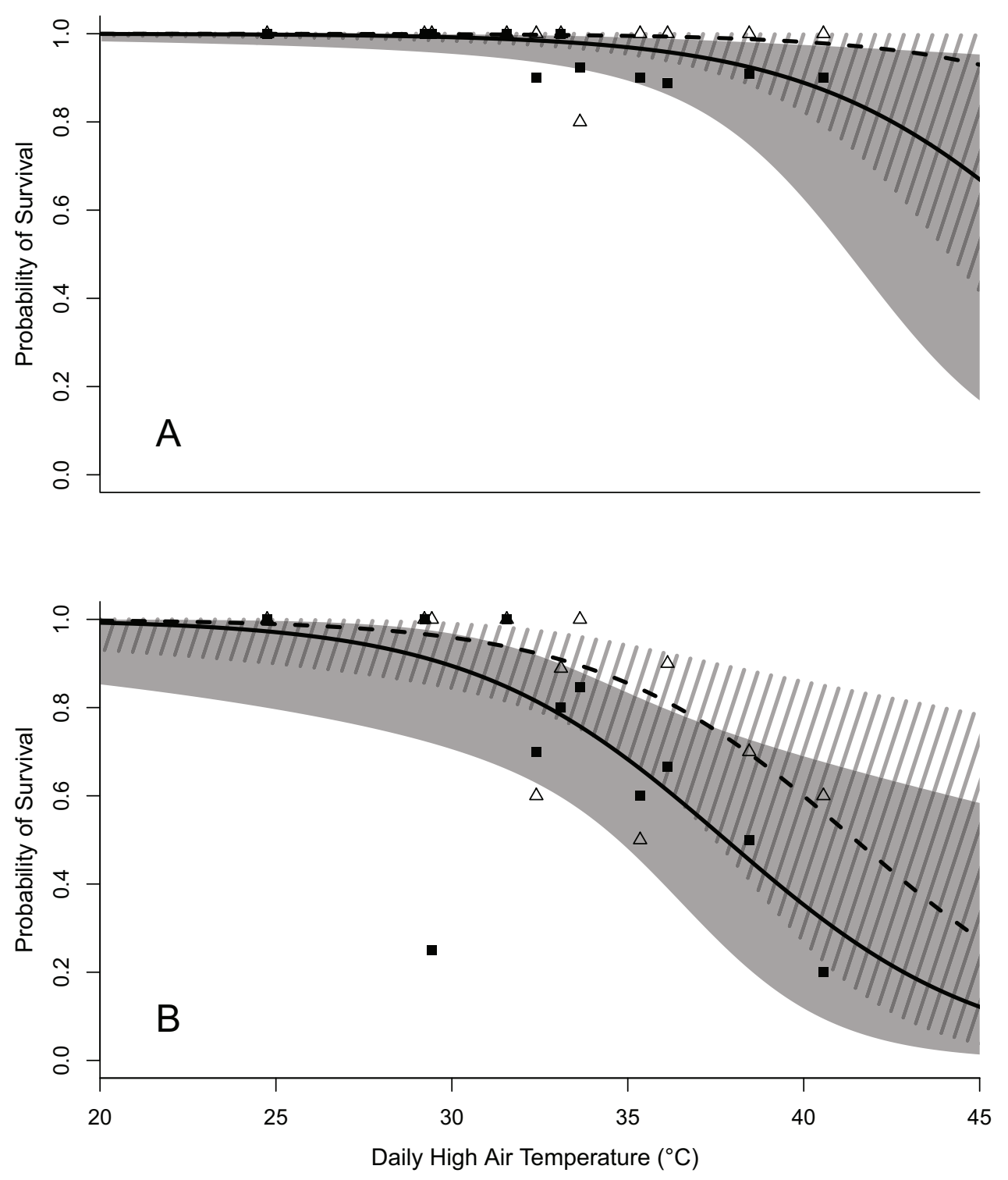

Figure 3: Effects of color and daily high temperature on survival of Battus philenor caterpillars over $24 \mathrm{~h}$ in field enclosures with $(A)$ or without $(B)$ access to refuges. Dashed lines, open triangles, and striped areas represent red caterpillars; black solid lines, solid squares, and shaded areas represent black caterpillars. Each point represents the average survival of 8-10 caterpillars per treatment on each of 11 days, for a total of $n=400$. Lines represent predicted survival, with shaded regions representing $95 \%$ confidence intervals.

a superior response to both large magnitudes and high rates of temperature change. However, the superiority of thermal refuge-seeking behavior comes with substantial costs. To seek a refuge, the caterpillar must leave its ground-hugging host and cannot eat during this time. Refuge seeking can last multiple hours, a long-enough period of starvation to slow growth in other caterpillars, leading to prolonged development or decreased adult size (Stockhoff 1991; Tammaru et al. 2004). For B. philenor caterpillars, leaving the host carries the added risk of not relocating it (Rausher 1979) and thus dying. We have shown that color change reduces this need to leave the host, avoiding these costs and providing caterpillars with more time to eat, which should facilitate faster growth.

Color change has its own potential limitations. Color change could have physiological costs associated with pigment production, particularly for melanin, which is used to produce dark colors but is also associated with immune function in insects (Strand and Pech 1995; Wilson et al. 2001; Armitage and Siva-Jothy 2005; Cotter et al. 2008). Battus philenor, however, has few parasitoids, mostly in the pupal stage (Sime 2000), so trade-offs between color and immunity 
Table 2: Effects of color, refuge availability, daily high air temperature, and plant height on likelihood of survival of Battus philenor caterpillars in field enclosures over $24 \mathrm{~h}$

\begin{tabular}{lrrrc}
\hline & Coefficient & SE & \multicolumn{1}{c}{$\chi^{2}$} & $P$ \\
\hline Color $^{\mathrm{a}}$ & 1.010 & .428 & 9.22 & .0024 \\
Refuge $^{\mathrm{b}}$ & 2.685 & .601 & 52.15 & $<.00001$ \\
Daily high temperature $\left({ }^{\circ} \mathrm{C}\right)$ & -.274 & .106 & 7.64 & .0057 \\
Plant height $(\mathrm{cm})$ & .368 & .131 & 9.35 & .0022 \\
Color $^{\mathrm{a}} \times$ refuge $^{\mathrm{b}}$ & .868 & 1.195 & .597 & .440 \\
\hline
\end{tabular}

${ }^{\text {a }}$ Red versus black.

b Available versus unavailable.

are likely to be minor for larvae, if present at all. Instead, the primary disadvantage of color change is that B. philenor can change color only when it molts, which requires a day or more even under ideal lab conditions. Rather than providing an instant response to the environment, morphological plasticity often has some amount of lag time, as does learning in behavior (Snell-Rood 2013; Foster et al. 2015). During this lag time between a change in the environment and an appropriate change in the phenotype, an organism will be expressing the wrong phenotype for its environment and not be gaining the benefits of plasticity, and if the environment changes rapidly enough, a slow plastic response may provide no benefit at all (Padilla and Adolph 1996; Gabriel et al. 2005). Rapid environmental changes will instead favor rapidly reversible plastic responses to keep up with them (Padilla and Adolph 1996), refuge-seeking behavior in this case. When temperature changes too greatly or quickly for color change to keep up with it, such as between night and day, refugeseeking behavior can provide this fast response, while when temperature changes persist for multiple days, such as seasonal changes, color change can provide a potentially more efficient long-term response, allowing caterpillars to avoid the costs of refuge seeking and stay on their hosts longer. In this way, these two plastic responses to high temperatures can complement each other.

As we found in B. philenor, complementarity of different plastic responses for different rates of temperature change should be common in other ectotherms. For both temperature and other environmental factors, the variation in the rate of both the environmental change and the plastic responses to that change that we found in B. philenor is not at all unusual. Temperature, like most aspects of the environment, varies on many different timescales, from hours to days to months to years, and so does the frequency with which plastic changes can occur. Behavioral and physiological responses are often rapid, while morphological and life-history changes tend to take much longer (Foster et al. 2015). Behavior is generally predicted to have the greatest potential to modify temperature (Stevenson 1985), but reliance on behavior can restrict which microhabitats an animal uses and how, leading to substantial costs, such as reduced opportunity for foraging or increased exposure to predators (Huey and Slatkin 1976; Casey 1993). Morphological and physiological changes may be slower or of smaller effect but can allow an organism to continue to use its preferred microhabitat.

If different plastic responses to temperature are rarely synergistic and typically complement each other instead, as we believe should be the case, this will limit an organism's ability to respond to thermal change. The maximum temperatures an organism can survive may be much less than we would predict if we simply considered the changes independently and assumed that their effects were additive. Recent studies have emphasized the importance of accounting for behavioral thermoregulation in modeling how ectotherm species will respond to climate change and determining what species or regions are most vulnerable to predicted changes (Kearney et al. 2009; Sunday et al. 2014). Others have pointed out that nonbehavioral plastic responses to climate change should be considered alongside behavior when assessing the vulnerability of species to climate change (Gvozdik 2012; Huey et al. 2012), and here we provide one of the first relevant empirical examples of how different plastic responses to temperature can affect each other's function, potentially reducing the species' overall capacity to respond to climate change.

In addition to changes in average temperatures, daily variation in temperature is also changing, although in different directions in different places (Karl et al. 1993; Lobell et al. 2007; IPCC 2013; Qu et al. 2014; Wang and Dillon 2014). As we have shown, different plastic traits respond to environmental change on different timescales. Some plastic traits will be more important in responding to increases in average temperature (e.g., color change), while others will be more valuable in coping with any increases in the daily variability of temperature (e.g., thermoregulatory behavior). Ultimately, although these different plastic changes may not work better when expressed simultaneously, they will both be important in responding to different aspects of temperature change. Beyond temperature, whether different plastic responses to other environmental changes tend to be synergistic or complementary remains an open question. The complementarity shown here may be common in other systems, particularly where plastic changes vary in response speed, and future research can test these hypotheses in new species and contexts using an approach similar to ours.

\section{Acknowledgments}

We would like to thank G. Barron-Giffords and L. Venable for use of equipment and the Santa Rita Experimental Range for permission to conduct our experiments there. S. Galuska and S. Linhart assisted with the data collection. R. Easter, S. Galuska, K. Geiger, K. Gleckler, T. Mccormack, and E. Moreno assisted with raising caterpillars. The manuscript bene- 
fited from the comments of three anonymous reviewers. Funding was provided by National Science Foundation Graduate Research Fellowship Program grant DGE-1143953.

\section{Literature Cited}

Ahnesjö, J., and A. Forsman. 2006. Differential habitat selection by pygmy grasshopper color morphs; interactive effects of temperature and predator avoidance. Evolutionary Ecology 20:235-257.

Armitage, S. A. O., and M. T. Siva-Jothy. 2005. Immune function responds to selection for cuticular colour in Tenebrio molitor. $\underline{\mathrm{He}-}$ redity 94:650-656.

Auld, J. R., A. A. Agrawal, and R. A. Relyea. 2010. Re-evaluating the costs and limits of adaptive phenotypic plasticity. Proceedings of the Roval Societv B 277:503-511.

Bakken, G. S. 1992. Measurement and application of operative and standard operative temperatures in ecology. American Zoologist 32: 194-216.

Bakken, G. S., W. R. Santee, and D. J. Erskine. 1985. Operative and standard operative temperature: tools for thermal energetics studies. American Zoologist 25:933-943.

Boersma, M., P. Spaak, and L. De Meester. 1998. Predator-mediated plasticity in morphology, life history, and behavior of Daphnia: the uncoupling of responses. American Naturalist 152:237-248.

Casey, T. M. 1993. Effects of temperature on foraging of caterpillars. Pages 5-28 in N. E. Stamp and T. M. Casey, eds. Caterpillars: ecological and evolutionary constraints on foraging. Chapman \& Hall, New York.

Cheverud, J. M. 1996. Developmental integration and the evolution of pleiotropy. American Zoologist 36:44-50.

Cotter, S. C., J. P. Myatt, C. M. H. Benskin, and K. Wilson. 2008. Selection for cuticular melanism reveals immune function and lifehistory trade-offs in Spodoptera littoralis. Journal of Evolutionary Biology 21:1744-1754.

DeWitt, T. J., A. Sih, and D. S. Wilson. 1998. Costs and limits of phenotypic plasticity. Trends in Ecology and Evolution 13:77-81.

Forsman, A. 2000. Some like it hot: intra-population variation in behavioral thermoregulation in color-polymorphic pygmy grasshoppers Evolutionary Ecology 14:25-38.

Forsman, A., K. Ringblom, E. Civantos, and J. Ahnesjö. 2002. Coevolution of color pattern and thermoregulatory behavior in polymorphic pygmy grasshoppers Tetrix undulata. Evolution 56:349360.

Foster, S. A., M. A. Wund, M. A. Graham, R. L. Earley, R. Gardiner, T. Kearns, and J. A. Baker. 2015. Iterative development and the scope for plasticity: contrasts among trait categories in an adaptive radiation. Heredity 115:335-348.

Gabriel, W., B. Luttbeg, A. Sih, and R. Tollrian. 2005. Environmental tolerance, heterogeneity, and the evolution of reversible plastic responses. American Naturalist 166:339-353.

Ghalambor, C. K., J. K. McKay, S. P. Carroll, and D. N. Reznick. 2007. Adaptive versus non-adaptive phenotypic plasticity and the potential for contemporary adaptation in new environments. Functional Ecology 21:394-407.

Gvozdik, L. 2012. Plasticity of preferred body temperatures as means of coping with climate change? Biology Letters 8:262-265.

Huey, R. B., M. R. Kearney, A. Krockenberger, J. A. M. Holtum, M. Jess, and S. E. Williams. 2012. Predicting organismal vulnerability to climate warming: roles of behaviour, physiology and adapta- tion. Philosophical Transactions of the Roval Societv B 367:16651679.

Huey, R. B., and M. Slatkin. 1976. Costs and benefits of lizard thermoregulation. Quarterly Review of Biology 51:363-384.

IPCC. 2013. Climate change 2013: the physical science basis. Working Group I contribution to the Fifth Assessment Report of the Intergovernmental Panel on Climate Change. T. F. Stocker, D. Qin, G.-K. Plattner, M. Tignor, S. K. Allen, J. Boschung, A. Nauels, Y. Xia, V. Bex, and P. M. Midgley, eds. Cambridge University Press, Cambridge. doi:10.1017/CBO9781107415324.

Karl, T. R., P. D. Jones, R. W. Knight, G. Kukla, and N. Plummer 1993. Asymmetric trends of daily maximum and minimum temperature. Bulletin of the American Meteorological Society 74:10071023.

Kearney, M. R., R. Shine, and W. Porter. 2009. The potential for behavioral thermoregulation to buffer "cold-blooded" animals against climate warming. Proceedings of the National Academy of Sciences of the USA 106:3835-3840.

Kingsolver, J. G. 1985. Thermoregulatory significance of wing melanization in Pieris butterflies (Lepidoptera: Pieridae): physics, posture, and pattern. Oecologia (Berlin) 66:546-553.

- 1987. Evolution and coadaptation of thermoregulatory behavior and wing pigmentation pattern in pierid butterflies. Evolution 41:472-490.

. 2009. The well-temperatured biologist. American Naturalist 174:755-768

Kingsolver, J. G., and R. B. Huey. 1998. Evolutionary analyses of morphological and physiological plasticity in thermally variable environments. American Zoologist 38:1-15.

Kishida, O., G. C. Trussell, A. Mougi, and K. Nishimura. 2010. Evolutionary ecology of inducible morphological plasticity in predatorprey interaction: toward the practical links with population ecology. Population Ecology 52:37-46.

Lindstedt, C., L. Lindström, and J. Mappes. 2009. Thermoregulation constrains effective warning signal expression. Evolution 63:469478.

Lobell, D. B., C. Bonfils, and P. B. Duffy. 2007. Climate change uncertainty for daily minimum and maximum temperatures: a model inter-comparison. Geophysical Research Letters 34:1-5.

McCollum, S. A., and J. Van Buskirk. 1996. Costs and benefits of a predator-induced polyphenism in the gray treefrog Hyla chrysoscelis. Evolution 50:583-593.

Nice, C. C., and J. A. Fordyce. 2006. How caterpillars avoid overheating: behavioral and phenotypic plasticity of pipevine swallowtail larvae. Oecologia (Berlin) 146:541-548.

Nielsen, M. E. 2016. Interactions among multiple plastic traits in caterpillar thermoregulation, $\mathrm{PhD}$ diss. University of Arizona, Tucson.

Nielsen, M. E., and D. R. Papaj. 2015. Effects of developmental change in body size on ectotherm body temperature and behavioral thermoregulation: caterpillars in a heat-stressed environment. Oecologia (Berlin) 177:171-179.

- 2017. Data from: Why have multiple plastic responses? interactions between color change and heat avoidance behavior in Battus philenor larvae. American Naturalist, Dryad Digital Repository, http://dx.doi.org/10.5061/dryad.ph826.

Padilla, D. K., and S. C. Adolph. 1996. Plastic inducible morphologies are not always adaptive: the importance of time delays in a stochastic environment. Evolutionary Ecology 10:105-117.

Piersma, T., and J. Drent. 2003. Phenotypic flexibility and the evolution of organismal design. Trends in Ecology and Evolution 18:228-233. 
Qu, M., J. Wan, and X. Hao. 2014. Analysis of diurnal air temperature range change in the continental United States. Weather and Climate Extremes 4:86-95.

Rausher, M. D. 1979. Egg recognition: its advantage to a butterfly. Animal Behavior 27:1034-1040.

Relyea, R. A. 2004. Integrating phenotypic plasticity when death is on the line: insights from predator-prey systems. Pages 176-190 in M. Pigliucci and K. Preston, eds. Phenotypic integration: studying the ecology and evolution of complex phenotypes. Oxford University Press, Oxford.

Schlichting, C. D. 1989. Phenotypic integration and environmental change. Bioscience 17:667-693.

Scott, R. L., G. D. Jenerette, D. L. Potts, and T. E. Huxman. 2009. Effects of seasonal drought on net carbon dioxide exchange from a woody-plant-encroached semiarid grassland. Journal of Geophysical Research 114:G04004. doi:10.1029/2008JG000900.

Sime, K. R. 2000. Two new records of pimpline ichneumonids attacking Battus philenor Linnaeus (Lepidoptera: Papilionidae). Journal of Hymenopteran Research 9:210-212.

Sime, K. R., P. P. Feeney, and M. M. Haribal. 2000. Sequestration of aristolochic acids by the pipevine swallowtail, Battus philenor (L.) evidence and ecological implications. Chemoecology 10:169-178.

Snell-Rood, E. C. 2013. An overview of the evolutionary causes and consequences of behavioural plasticity. Animal Behaviour 85:10041011.

Stevenson, R. D. 1985. The relative importance of behavioral and physiological adjustments controlling body temperature in terrestrial ectotherms. American Naturalist 126:362-386.
Stockhoff, B. A. 1991. Starvation resistance of gypsy moth, Lymantria dispar (L.) (Lepidoptera: Lymantriidae): tradeoffs among growth, body size, and survival. Oecologia (Berlin) 88:422-429.

Strand, M. R., and L. L. Pech. 1995. Immunological basis for compatibility in parasitoid-host relationships. Annual Review of Entomology 40:31-56.

Sunday, J. M., A. E. Bates, M. R. Kearney, R. K. Colwell, N. K. Dulvy, J. T. Longino, and R. B. Huey. 2014. Thermal-safety margins and the necessity of thermoregulatory behavior across latitude and elevation. Proceedings of the National Academy of Sciences of the USA 111:5610-5615.

Tammaru, T., S. Nylin, K. Ruohomäki, and K. Gotthard. 2004. Compensatory responses in lepidopteran larvae: a test of growth rate maximization. Oikos 107:352-362.

Van Buskirk, J., and S. A. McCollum. 2000. Functional mechanisms of an inducible defense in tadpoles: morphology and behaviour influence mortality risk from predation. Journal of Evolutionary Biology 13:336-347.

Wang, G., and M. E. Dillon. 2014. Recent geographic convergence in diurnal and annual temperature cycling flattens global thermal profiles. Nature Climate Change 4:1-5.

Wilson, K., S. C. Cotter, A. F. Reeson, and J. K. Pell. 2001. Melanism and disease resistance in insects. Ecology Letters 4:637-649.

Associate Editor: Edmund D. Brodie III Editor: Alice A. Winn

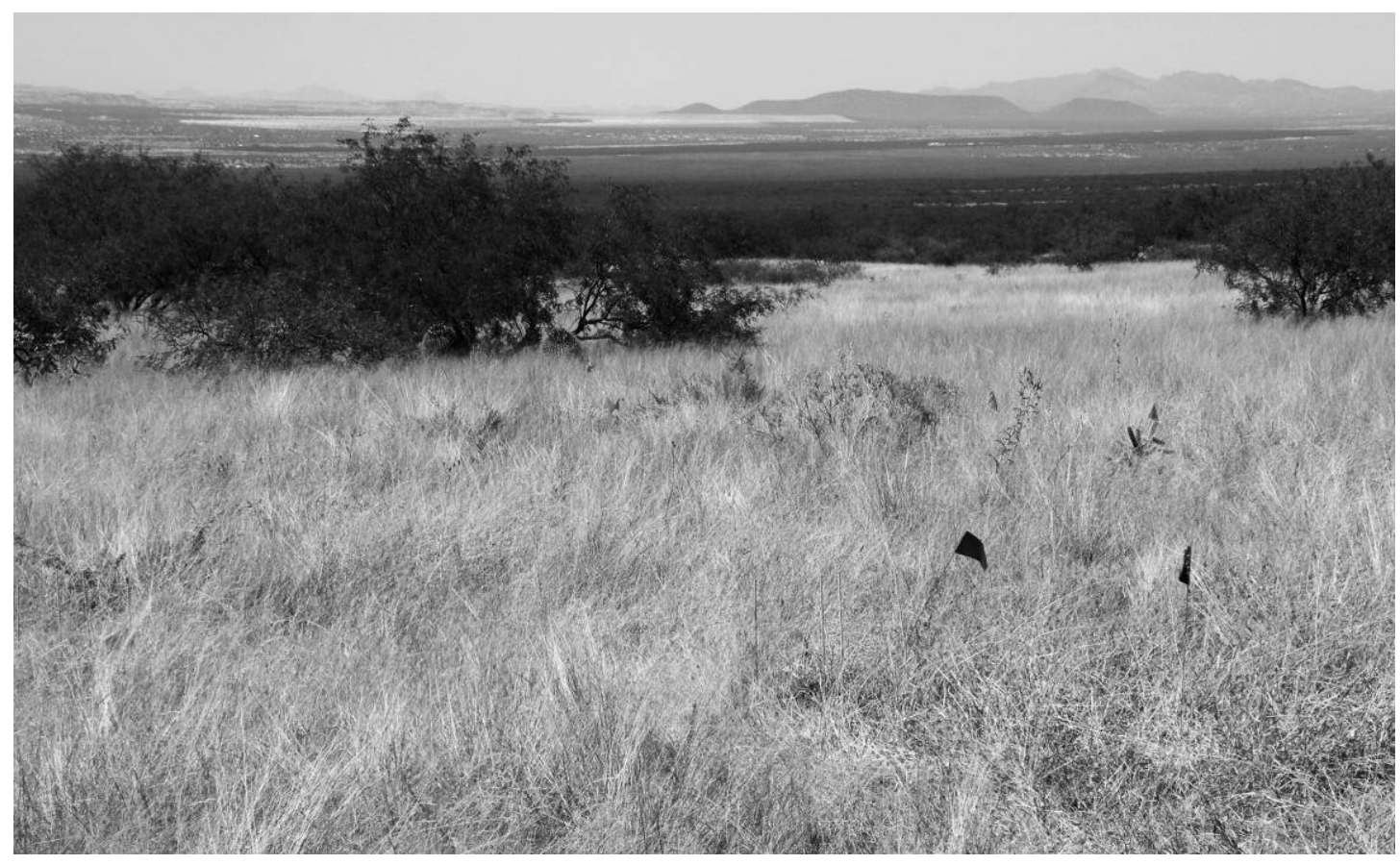

Area of the Santa Rita Experimental Range in southern Arizona where this study was conducted. Flags mark the locations of experimental enclosures for the experiment with live caterpillars. Photo credit: Matthew Nielsen. 